\section{SOCIAL STRATIFICATION IN BRITISH SOCIETY}

A

$T$ the extended general meeting of the British Psychological Society held at the Municipal Training College, Brighton, during April 9-12, the Section of Social Psychology arranged a symposium, under the chairmanship of Prof. M. Ginsberg, on the theme of "Social Stratification".

Prof. T. H. Pear, professor of psychology in the University of Manchester, read a paper on "Psychological Aspects of English Social Stratification". $\mathrm{He}$ began by pointing out that sociologists approach the subject of social stratification by making general statements about classes, comparing and contrasting them, but with very few illustrations from actual instances or research studies. This sort of specific information is regarded as rather a matter for journalists or novelists; but journalists and novelists are often biased by selection and personal preferences. Perhaps the roots of the difficulty lie deeper. Is it part of the general tendency of sociologists to eschew the concrete case-to be nomothetic instead of epigraphic? Anyone who ventures into this area of psychology puts himself in a position to be shot at from both sides simultaneously. The subject of the symposium, therefore, is almost untouched by psychologists and attracts surprisingly little attention from sociologists. There are social forces which make it difficult for a professional thinker to regard his own position in society objectively, and fully to comprehend its meaning in a wider social pattern. Severe taboos are imposed upon detailed consideration of social status (especially of persons living in any but the 'top' and 'bottom' layers of society). This unanalysed acceptance of social status ('knowing one's place') partly explains the sociologist's and psychologist's neglect of social stratification. So English social psychology is, on the whole, an account by middle-class writers of middle-class behaviour.

English social stratification is not what it was in 1939 and it will change considerably when peace comes, according to Prof. Pear. It is, however, necessary to record that as in Disraeli's time there are still two Englands. From many directions we hear that after the War there will be great changes in the English social classes. In one sense this is a platitude. All modern wars cause social change; this is what they are fought for. Social stratification will be less, and the lines of demarcation less clear. At the beginning of this War, some urged that it should be fought for the 'English way of life', describing it in a manner which might be recognized by their friends, if not by the majority of the English. Since then, many have pointed out that no national way of life ever completely survives a great war ; relatively few could wish our social structure to be exactly restored-cracks, moss, mildew and all.

Prof. Pear then went on to discuss social differences as shown by language. Each class uses characteristic terms of approval, disapproval, endearment, enthusiasm and boredom, and each disapproves or ridicules the choice of others. Euphemisms, too, are classlabels. Perhaps most of these are used by the middle (especially the lower-middle) class. Of the learnt phrases which especially indicate social strata the emollient group are the most striking. A good diplomat has many in stock, and knows when to produce the right one. They are used to begin, interrupt or end a conversation, to refuse or decline a request, suggestion or invitation; to correct a misstatement, to oppose a proposition without rancour, to adduce incontrovertible if unwelcome evidence, to accost a stranger, encourage a shy person or reprove a backslider. One social group may inaccurately attribute 'bad' speech to another. American journalists, when they 'quote' English working-class speech, are apt to write it without aspirates, yet in many parts of industrial England the ' $h$ ' is seldom dropped. With such warnings in mind, it may be said that difference in vowelpronunciation is an important mark of social class. The Cockney modifies all the English vowels, usually transforming them into diphthongs. The auditory 'aspect' of speech is perhaps more important than the visual accompaniment, facial expression, gesture and posture. The comparative absence of facial expression and gesture from the speech-behaviour of the English 'ruling classes' may be a sign of social stratification.

On reading attempts made between 1918 and 1939 to explain war in terms of human experience and behaviour, Prof. Pear has been driven to conclude that most of them were conceived from an upper. class point of view. Underlying them is the assumption that when war is declared the author will take -or be holding-a commission. Few, especially those who 'explain' the stirring up of war in peacetime as due to aggressiveness, ask themselves how much the poorer people know about the nations for whom, after war has broken out, they are exhorted to feel emotions specified by the propagandists. In the past, privilege may have exercised good influences in many directions, yet during our lifetime its shortcomings have been increasingly obvious. To-day it seems to be falling into disfavour all over the world. Yet the difference ought to be clearly recognized between lessening privilege and decreasing tolerance of individual differences. Prof. Pear urged social psychologists to study social phenomena, both in the upper and the lower classes. For gentle manners are not the result of an accident, and he feels it would be a tragedy if we lost them.

Mr. Tom Harrisson, of Mass Observation, contributed to the symposium a paper on "Class Consciousness and Class Unconsciousness". There is no doubt that there are differences between different groups of the community, but after spending five years in making Mass-Observation studies of ordinary people in all parts of the country, he feels the extent of class difference has been exaggerated. Some sections of the community are richer or poorer, more or less educated, but the conception of clearly divided self-conscious groups is of doubtful validity. The class who are really 'class conscious' are the small upper-class group, who feel deeply aware of the mass of poorer and less educated prople 'below' them, and often fear them. Many of the characteristics of 1942 Britain are due to this underlying 'fear of the masses' among our leaders, and their consequent tendency to treat working people as if they are somehow stupid and dangerous, to be kept in good humour but also to be kept in place. Among much the largest section of the community-the manual workers-there is little class consciousness ; thare are many divisions within the working class, as regards mentality and outlook. There are marked differences and conflicts, for example, within a cotton mill, and even within the team of three working on one cotton operation-the spinner, the side piecer and the little piecer. 
This is not to say that there are not big differences between different sections of the community. But these differences are not necessarily class differences; there are often much bigger age or sex or temperament differences on the same subject. In general, the basic distinction is the amount of money owned or earned, and connected with this the degree of education. In observational studies of non-voting, over a series of municipal elections in which there were candidates of 'middle-class' and 'working-class' parties, it was found that 38 per cent of the so-called upper-class did not vote, 42 per cent of middle-class and 48 per cent of working-class. In a recent investigation on political attitudes, it was found that while most middle-class people were, for example, able to name at least one living Liberal politician, the majority of working people could not name one at all. Again, the degree to which people hold an opinion on propaganda films decreases sharply as one descends the economic scale. Many other examples could be given from MassObservation's researches, said Mr. Harrisson, to illustrate differences of knowledge and reaction between those who ended their education at the elementary stage and the better-off minorities. Cash differences inevitably produce other differences. But to term these indiscriminately 'class differences' obscures the fact that there are probably few inherent differences within the individual which cannot be eradicated in various ways, often quickly.

Mr. Harrisson thinks that the mental gulf between the upper classes and the working classes has been gradually exaggerated in the minds especially of the upper classes, though this does not make it any less significant psychologically for them. We have seen lately, in the rapid growth of works councils in war industry, how much can be done in a factory simply by bringing together around a table once a month some representative workers and managers. In the past most firms have assumed that the distinction between management and worker is absolute and essential; in war this distinction is found to be obstructive to maximum effort, and it has now been proved to be (to a considerable extent) avoidable.

Mr. Harrisson considered that the most useful symbol of British social structure is the familiar pyramid, with the King on the top, the mass of $£ 3-\mathrm{a}$ week people at the base. There is a constant tendency among those at the bottom to try to climb up towards the top. The general tendency is to admire those at the top, seldom to resent them.

Mr. Harrisson described some ways in which working people in "Worktown" canalize our culture urge to go up the social scale. Every week-end Worktowners spend an extra quantity of money in special pleasures, such as drinking beer in the public lounge, where the same beer costs 1 d. more than it does in the 'vault', used on week-days. During the week anybody wearing a bowler hat is either middle-class or a mourner. At the week-end, anybody and everybody may wear a bowler and look thoroughly middle-class. The week-end cycle is a regular process of class elevation, and men who never think of wearing a tie during the week may have a gold tie-pin on Sunday. Secondly, there is the cycle of the year, for which people save up every week, to take one week's holiday at Blackpool or elsewhere, generally at a much higher level of expenditure, environment and social prestige than they have ever enjoyed in their home town. One week a year they are able to live on a higher rung of the ladder.

Thirdly, there is the cycle of life. Many working people put aside money every week in their lives so that they can be buried with rich pomp and ceremony at their deaths. Moreover, the graves in Worktown cemetery are graded into four classes, according to the distances from the path and therefore the number of people who see your tombstone. Class $I$ is very expensive and beside the main path. It is the ambition of many poor people to have in death a class position unattainable in life.

Prof. J. C. Flugel, assistant professor of psychology in University College, London, read a paper in the symposium on "Class Mind and Group Mind". $\mathrm{He}$ agreed with much of what Mr. Tom Harrisson had said. But we are forced to use the term 'class' because there is no better one available at present ; in using it we must constantly remember that class is nothing rigid, but something very fluid. Psychologists have not tried to investigate the problem of class-consciousness systematically, though there has been a certain amount of work on racial and other attitudes. One is sometimes inclined to believe that the term 'class', as H. G. Wells remarks, has degenerated into a mere weapon or term of abuse. Class may be fixed by a class hierarchy, but otherwise it is difficult or impos. sible to define. Class fulfils only partly the criteria of McDougall's "highly organized group", that is a group with a common purpose, continuity, some adequate idea of itself, interaction or rivalry with other groups, a body of common traditions, internal organization of the group, including specialization and differentiation. Marxism aims at bringing about an accentuation of these criteria, especially a common purpose, an adequate idea of the class grouping, and interactional rivalry. It assumes that there are only two classes and there will be an increasing dichotomy. In this Marxism has proved to be wrong, said Prof. Flugel; not only has 'class' become increasingly continuous, but also class distinctions are cut across by numerous other groups, the boundaries of which are drawn on other lines. Many workers are now small-scale capitalists; many in the general election of 1931 had the capitalist side of their feelings (fear about savings, etc.) accentuated so much that it swamped the workers' side (Labour sympathies, etc.).

Prof. Flugel felt that class distinctions are becoming more confused, rather than less, and that Marx's brilliant theory has not worked out in practice in Great Britain. Employers have increasingly sought to cultivate new loyalties within classes by profit sharing, bonus systems, welfare schemes, and so on. Then there is the rise of the manager in all his different grades; the increase of minor bureaucrats and officials; the small business man running his own business or shop, who may be more of a property owner than the salaried manager, but inferior in wealth to the skilled worker ; such people feel interest in the nature of their business rather than their class.

Prof. Flugel went on to point out some changes in social stratification. A new sense of interest in and guilt about the conditions of the poor has occurred in the upper classes, and increasingly within the past few years. The realization of this responsibility is largely due to the rise of Socialism, but is also in opposition to Socialism. Then, working people have become more conscious of their increased opportunity to rise in the social ladder, though it is still limited. Workers want to belong to the upper class, rather than to destroy it.

Some connexions between social stratification and Freudian theory were finally suggested by Prof. Flugel. The upper class group compare, from the 
workers' point of view, with the 'ego-ideal'. This would explain to some extent three contradictory attitudes towards the upper class-the attitude of wanting to rebel against it, the attitude of wanting to attain it, and the attitude of wanting to submit to it. On the other hand, pure class-consciousness in the Marxist sense stresses only companionship in a continuation of the sibling relationship, the 'id'. But we also need the child-adult (parent) relationship, the 'super-ego'. Now all revolutions towards one class lead to dictatorships, and these are thereby socially unstable. A revolutionary movement can scarcely be as morally satisfying as a 'patriotic' movement.

Summing up, Prof. Ginsberg said that he felt the Marxist point of view, which he by no means wholly accepts, had been rather underestimated in discussion and that there are aspects of it which still throw light on present conditions. There is a certain reality in 'class', in so far as 'you feel at home' with somebody of your own class. There is much else that can be said; what is needed now is more thoughtful study.

\section{ANIMAL HUSBANDRY IN INDIA*}

\author{
By SIR ARTHUR OLVER, C.B., C.M.G. \\ Royal (Dick) Veterinary College, Edinburgh
}

$I^{\mathrm{T}}$ would be quite impossible to gain a clear idea of the complexity of the problems facing animal husbandry in India without some understanding of the special factors conditioning the subject in India. For example : (1) Religious and traditional prejudices and customs. (2) Effect of the density of the population and the low purchasing power of the cultivators on farming practice. (3) General lack of appreciation of the fundamental principles which underlie proper breoding, feeding and management, and the great need which exists for a properly balanced system of land utilization. (4) Lack in most Provinces and Dtates of any expert animal husbandry organization devoted solely to the interests of livestock. (5) Annual droving of millions of dealers' cattle from north to wuth of India.

Slaughter. The cow is a semi-sacred animal and must not be slaughtered. In strict Hindu communities, it is not permissible to give a merciful release even to a fatally injured and suffering animal. These inhibitions are productive of the most far. reaching difficulties and make it impracticable to carry on dairying or stock breeding on strictly commercial lines.

Castration. Until comparatively recently, stock owners were unwilling to castrate their cattle at an early age, though the males and females run together on village grazing grounds. This objection is now being overcome, and castration of inferior animals is carried out on a large scale by Provincial veterinary departments. It cannot, however, be too much or too often emphasized that no lasting progress can be expected in livestock improvement until arrangements are made for controlled mating, and for the proper feeding and management of breeding females and young stock.

Grazing areas. Though highly desirable, the im. provement of such grazing areas as remain is not a solution of the cattle-feeding problem. The best of these areas tend to be taken up for cultivation, and

- Substance of a lecture before the India and Burma Section of the Royal Society of Arts, delivered on March 13. in any event, cultivators ought to aim at devoting a portion of their holdings to fodder crop production ; thereby producing better stock and more milk, and helping to maintain the fertility and physical condition of the soil. Without such a change of system -where necessary-progressive degeneration of cattle seems eertain to follow the gradual disappearance of good grazing lands on which the better cattle are at present bred.

Pinjrapoles and Gaushalas. The semi-religious pinjrapoles and gaushalas which are maintained in most cities throughout India have in many cases become anything but the homes of rest and comfort for derelict animals they are intended to be. By arranging for competent management and by breeding from the best of the cows and selling their milk, it has been shown that conditions can be greatly improved and profits made. Further, by taking up land for cultivation outside the city, the extra funds thus obtained can be utilized, to great advantage, to provide fodder crops and grazing for the hopelessly derelict and for the better feeding of the milking herd and young stock. By using selected sires, valuable young bulls were also produced, which should be of considerable value to breeders in the vicinity. These institutions could thus be made valuable demonstration centres all over India, and in addition to their great educational value, would save large numbers of quite good milch cows which are com. mitted to their care.

Density of population. Owing to the smallness of the holdings and the low purchasing power of the individual, it has generally been considered imprac. ticable for the Indian ryot to produce fodder crops for the proper feeding of his cattle, or to produce or purchase the increased supplies of milk which are essential for the health and proper development of the people. The tendency has been to consider that the only practicable policy is to produce more and more crops for sale or direct human consumption. As a result, soil fertility and humus content have been greatly depleted in many areas and enormous damage is being done by denudation, owing to removal of cover and humus from the soil. There seems, however, to be no reason why, by a suitable system of mixed farming, the ryots in suitable areas should not obtain as great money returns as under the present system of devoting their entire holdings to crops and, in addition, better stock and an invaluable supply of milk and dairy products for their families. Experiments undertaken to test this view have in fact shown that by substituting mixed farming, including milk production, for the mere raising of crops for sale, agriculture in many parts of India could be raised to a higher level.

Dung burning and the manurial value of livestock. Throughout the drier parts of India the custom of burning cow dung for fuel is a serious handicap to agriculture. A great deal of manurial value is lost ; the soil is deprived of humus; and, as cattle are not usually herded on the land due for cultivation, the manurial value of their urine is also lost.

Moreover, under the present system, village grazing grounds become so trodden and infected with disease that it is impossible to breed or maintain any but the most stunted stock on them.

In the absence of available firewood, the burning of cow dung seems bound to continue, but it is clear that more of the manurial value could be made available for crop production if cattle were better fed and maintained on the holdings, wherever possible. 